\title{
La fiscalidad eclesiástica frente a las exigencias financieras borbónicas y la guerra de Independencia: las diócesis de México, Michoacán y Guadalajara, $1790-1821$
}

\author{
por Élida María Tedesco
}

\begin{abstract}
This article studies the forced loans and donations which were imposed on the diezmo (tithe) of New Spain in order to support the financial needs generated by the European wars in the late eighteenth century and, later, by new demands during the War of Independence. Based on the documentation from four cathedral chapters (Mexico, Valladolid, Michoacán, and Guadalajara), the main purpose of this article is to identify changes in the level and distribution of tithe which were produced by the contribution to war spending in those years.
\end{abstract}

\section{INTRODUCCIÓN}

Con la imposición del diezmo sobre el mundo rural, ${ }^{1}$ se reprodujo en las Indias uno de los elementos propios del sistema fiscal de Antiguo Régimen: la existencia de una fiscalidad eclesiástica paralela e independiente de la del Estado. Se le reconoció a la Iglesia diocesana americana la capacidad de exigir a los particulares y a las instituciones un impuesto: el diezmo. ${ }^{2}$

La convivencia de las dos fiscalidades (la eclesiástica y la real) se dio sin mayores conflictos hasta el último tercio del siglo XVIII,

1 Mediante la donación papal de los diezmos de Indias a los Reyes Católicos en la Bula de Alejandro VI, Eximiae devotionis del 16 de diciembre de 1501.

2 Miguel Artola, Hacienda de Antiguo Régimen (Madrid 1982), p. 21. 
cuando las rentas decimales se vieron afectadas por demandas financieras de la Corona, destinadas a cubrir los gastos provocados por las guerras imperiales en Europa. Más tarde, durante la guerra de Independencia, las exigencias a la fiscalidad eclesiástica aumentaron como consecuencia de las contribuciones solicitadas por la Real Hacienda de la Nueva España, para el sostenimiento de las tropas realistas que luchaban contra los insurgentes. Además, con la situación bélica, el sistema de recaudación decimal, que hasta el momento se mantenía inalterado, fue trastocado por saqueos a las colecturías, la exigencia de contribuciones en dinero, semillas y ganado y la interrupción de las comunicaciones.

Los estudios históricos han destacado los efectos adversos de la guerra para los ingresos de la fiscalidad eclesiástica, ya sea por la importante extracción de recursos, por la descomposición de los sistemas de recaudación o por deterioro de la fidelidad decimal de los contribuyentes. En la línea de una creciente presión del fisco real sobre los diezmos, Marichal ha planteado para la Nueva España de las últimas décadas coloniales la progresiva sujeción de la fiscalidad eclesiástica a la Hacienda Real, mediante la transferencia de una porción cada vez mayor de la renta decimal a las arcas reales y el aporte de considerables préstamos y donativos de los cabildos de las catedrales. ${ }^{3}$ Otras aproximaciones a los efectos de la guerra en la recaudación decimal han sido realizadas en España. Dentro de estudios más amplios sobre la crisis de la fiscalidad de Antiguo Régimen se ha subrayado que durante la lucha contra la invasión francesa se produjo un fatal impago del diezmo, resultado de la demanda de recursos al campo, la utilización del diezmo como impuesto de guerra y del debilitamiento del poder recaudatorio de la Iglesia. ${ }^{4}$ En la misma línea del declive de la recaudación a causa de la guerra, la investigación de

3 Carlos Marichal, La bancarrota del virreinato. Nueva España y las finanzas del Imperio español, 1780-1810 (México, D.F. 1999).

4 Esteban Canales, "Diezmos y revolución burguesa en España": Ángel García Sanz/Ramón Garrabou (eds.), Historia Agraria de la España Contemporánea, tomo 1: Cambio social y nuevas formas de producción, 1800-1850 (Barcelona 1985), pp. 245274; Carlos Rodríguez López-Brea, "La crisis del antiguo régimen en el arzobispado de Toledo. El impago de diezmos, 1800-1820": Javier Donezar/Manuel Pérez Ledesma (eds.), Antiguo Régimen y liberalismo. Homenaje a Miguel Artola, tomo II: Economía y Sociedad (Madrid 1994), pp. 285-293; María Dolores Muñoz Dueñas, "Las resistencias al diezmo": Hacienda Pública Española, El fraude fiscal en la Historia de España (Madrid 1994), pp. 155-165. 
Bravo y Pérez para el arzobispado de México constituye un punto de referencia; atendiendo particularmente al funcionamiento de las administraciones o jurisdicciones de colectación, los autores examinan numerosos ejemplos de la turbación, de los saqueos y de las contribuciones forzosas que provocaron el decaimiento de la recolección del diezmo durante la lucha de la Independencia. ${ }^{5}$

Recuperando estos aportes, en este artículo se estudia la incidencia en la fiscalidad eclesiástica novohispana de la continua demanda de recursos decimales para financiar gastos de guerra en los últimos decenios de la colonia; específicamente se indagan los cambios en las formas de recolección y de distribución del diezmo generados por la sostenida exigencia fiscal y financiera de la guerra. Con este objetivo se analizan los aportes financieros (préstamos y donativos al Gobierno colonial), realizados con recursos decimales por los cabildos de las catedrales de México, Valladolid de Michoacán y Guadalajara en el periodo 1792-1820, y el desorden, los perjuicios y las disminuciones que sufrió la recaudación decimal durante la guerra de Independencia.

\section{LAS GUERRAS IMPERIALES Y LOS APORTES DEL DIEZMO NOVOHISPANO}

Frecuentes y costosos conflictos internacionales, junto a recursos insuficientes para llevarlos a cabo, fueron constantes en el gobierno de los Borbones a lo largo del siglo XVIII. La guerra de Sucesión, que definió el cambio dinástico (1701-1710), el esfuerzo por controlar de manera efectiva el monopolio de comercio con las posesiones americanas y los interminables conflictos bélicos resultado del Tercer Pacto de Familia (1761), alianza ofensiva y defensiva entre las dos potencias borbónicas que ató la política exterior española a la de Francia, convirtieron el gasto del Ejército y de la marina en el principal destino de las rentas de la Monarquía y determinaron el volumen de recursos que precisaba reunir la Hacienda. A fines del siglo, los conflictos bélicos en que se vio comprometida la Corona española se multiplicaron: guerras contra Inglaterra (1779-1783, 1796-1802, 1805-1808), confrontación con la Convención francesa (1793-1795)

5 Berenice Bravo/Marco Antonio Pérez, Una iglesia en busca de su independencia: el clero secular del arzobispado de México, 1803-1822 (tesis de licenciatura, Universidad Nacional Autónoma de México 2001). 
y, en la primera década del siglo XIX, la invasión napoleónica de la Península (1808-1814). ${ }^{6}$

El creciente agobio del erario obligó a la Monarquía a intentar reformas hacendísticas dirigidas a aumentar la recaudación fiscal y a estabilizar sus finanzas. Pero la reforma tributaria en España fracasó, limitándose finalmente a pequeñas modificaciones administrativas, a la imposición de recargos y al revalúo al alza de los encabezamientos. ${ }^{7}$ Los caudales americanos se hicieron cada vez más necesarios para cubrir los compromisos militares y financieros de la metrópoli, al grado de que "las remesas por cuenta de la real hacienda americana alcanzarían su nivel más alto en tres siglos de historia colonial". ${ }^{8}$ Sin embargo, las diversas medidas destinadas a aumentar las transferencias de plata de las tesorerías americanas y lograr mayores rendimientos fiscales no fueron suficientes y la Hacienda Real recurrió a la solicitud de empréstitos y donativos, buena parte de ellos a las corporaciones de las Indias (clero, consulados de comerciantes y cajas de comunidad). En Nueva España, ya por transferencias fiscales ya por contribuciones extraordinarias, la Iglesia fue el sector que mayores sumas aportó a la Corona. ${ }^{9}$

Si bien el rey había exigido contribuciones eclesiásticas para cubrir gastos militares antes de 1790 para los cabildos catedrales novohispanos, esa fue la fecha referida como inicio del deterioro de las rentas decimales a consecuencia de la demanda real de recursos extraordinarios. Así es posible encontrar, en la primera década del siglo XIX, documentos de los cabildos catedrales donde se evocan los aportes realizados a partir de 1790, con la intención de aminorar el efecto de las nuevas demandas de la Hacienda Real. Por ejemplo, en 1809 el

6 Para entender lo que esto significó en términos hacendísticos, Enrique Llopis señala que durante las últimas décadas del siglo los gastos de defensa se situaron por encima del 60 por ciento del gasto total del Estado español. Enrique Llopis Agelán, "Expansión, reformismo y obstáculos al crecimiento": Francisco Comín/Mauro Hernández/Enrique Llopis (eds.), Historia Económica de España. Siglos X-XX (Barcelona 2002), pp. 121-164, aquí p. 158. Véase también John Lynch, El Siglo XVIII (Barcelona 1991).

7 Josep Fontana, La quiebra de la monarquía absoluta, 1814-1820. La crisis del Antiguo Régimen en España (Barcelona 2002), pp. 12-46.

8 Marichal, La Bancarrota (nota 3), p. 23. Sobre las transferencias de las cajas americanas véase también John TePaske, "La crisis financiera del virreinato de Nueva España a fines de la colonia": Secuencia 19 (1991), pp. 123-140.

9 Ibidem, p. 6. 
cabildo de la catedral de México explicaba la corta cantidad con que participaría del empréstito solicitado:

"[por] hallarse esta santa iglesia tan sumamente gravada que el total de sus fondos no alcanzan ni aun para sus actuales créditos pasivos originados de donaciones hechas al rey [...] desde el año 92 hasta el presente." 10

Con la finalidad de financiar el conflicto contra los revolucionarios franceses, a fines de 1792 Carlos IV solicitó al clero americano un préstamo. Los miembros del cabildo catedral de México acordaron "que siendo tan piadosos los motivos de la presente guerra es justicia la contribución y donativo al soberano y que esta sea la maior que se pueda". Para ello, la mitra y el cabildo catedral metropolitano realizaron un donativo de 100.000 pesos en $1793 .{ }^{11}$

Una enorme aportación a este empréstito fueron los 300.000 pesos entregados a préstamo por el cabildo de la catedral de Guadalajara el 23 de febrero de 1793 (no se tiene información sobre cuál fue el ramo afectado por esta elevada contribución); en julio se dieron en calidad de donativo 10.000 pesos más por cada año que durara "la presente guerra"; aunque ésta terminó en 1795, el cabildo hizo un solo pago de los prometidos. ${ }^{12}$ Por su parte, los capitulares de la iglesia de Valladolid se suscribieron con 20.000 pesos, entregados el 2 de agosto, y con 20.000 pesos más en 1794 - ambas cantidades con el carácter de "donativo gracioso". ${ }^{13}$

En 1795 se renovaron las demandas imperiales para cubrir los compromisos militares y financieros. Mediante un oficio el virrey justificaba las nuevas contribuciones:

"[...] para sostener la justa guerra contra los franceses se han consumido inmensos caudales de los erarios del rey y sumas mui gruesas que han importado los generosos donativos y prestamos de sus amantes y leales vasallos [...] la actual guerra que encendida cada vez más, multiplica por presicion las causas de mayores y grandes gastos, exigiendo también por consecuencia los ultimos esfuerzos del verdadero zelo fidelidad y amor patriótico [...] ella pide nesezariamente la continuación de donativos y prestamos asta donde alcanzen nuestras facultades." 14

10 Archivo del Cabildo Catedral Metropolitano de México (en adelante ACCMM), Actas de cabildo (AC), libro 64, 24 de julio de 1809. Ejemplos similares para los otros obispados en: Archivo Histórico del Arzobispado de Guadalajara (en adelante AHAG), Haceduría, caja 4; y Archivo Capitular de Administración Diocesana Valladolid-Morelia (ACADVM), legajo 123

11 ACCMM, AC, libro 58, 26 de junio y 16 de julio de 1793.

12 AHAG, Haceduría, caja 4.

13 ACADVM, legajo 123.

14 ACCMM, AC, libro 58, 22 de abril de 1795. 
El cabildo eclesiástico de México discutió durante varias sesiones los "medios más eficaces" para dar cumplimiento a la nueva exigencia de recursos. Finalmente se resolvió ofrecer a su majestad un tanto por ciento de la gruesa decimal,

"[...] que se principiase a deducir desde el primer repartimiento que ha de hacerse en el próximo venidero junio, a todos los participes de ella excepto los dos reales novenos que se reservan y pertenecen a la misma corona".

Quedó acordado que el cabildo daría ese "diez por ciento durante el tiempo de la presente guerra y hasta el dia en que se tenga noticia de haverse terminado", cantidad que se estimaba ascendería a 25.000 pesos anuales. ${ }^{15}$

El capítulo de la iglesia de Guadalajara, visto el oficio del intendente, donó para auxilio de los gastos de guerra 6.000 pesos y ofreció las cantidades que correspondían a un año de la cuarta capitular de los diezmos de las jurisdicciones de Zapotlán, Colima y La Barca, ganadas en 1794, luego de un litigio con el obispado de Michoacán. Pero esas cantidades eran sólo hipotéticas porque aún no se verificaba la posesión de dichos distritos ni de sus diezmos. En mayo, se agregó un donativo de 16.000 pesos y un empréstito gracioso de 100.000 pesos. ${ }^{16}$ Por su parte, la iglesia de Valladolid realizó una aportación más modesta al requerimiento de 1795: dio en calidad de donativo para la guerra 10.000 pesos. ${ }^{17}$

En 1798 el rey otra vez manifestó a sus vasallos "las urgentes necesidades que padece el estado", ahora por la guerra naval con Inglaterra, y determinó el establecimiento en España y en Indias de dos suscripciones para la recaudación de nuevos recursos financieros: la primera a un "donativo voluntario en que las personas de todas clases y jerarquías ofrecerán espontáneamente qualesquiera cantidades en moneda y alhajas de oro y plata que les dicte su zelo por la causa pública", la otra a un préstamo patriótico sin interés, a reintegrarse durante los diez años siguientes al fin de la guerra. ${ }^{18}$

Informados por el arzobispo, los capitulares de la catedral de México realizaron un donativo de 70.000 pesos con fondos sacados

\footnotetext{
15 Ibidem.

16 AHAG, Haceduría, caja 4.

17 ACADVM, legajo 23.

18 ACCMM, AC, libro 59, 27 mayo 1798.
} 
del ramo de depósitos ${ }^{19}$ y de las existencias de la gruesa decimal. La catedral de Guadalajara se suscribió al donativo voluntario con 40.000 pesos (20.000 del cabildo y 20.000 del obispo) y el cabildo de Valladolid con 50.000 pesos. $^{20}$

En la primera década del siglo XIX, se sucedieron nuevas exigencias de donativos y préstamos al clero novohispano: en 1805, 1808, 1809 y 1810. En 1805, nuevamente en guerra con Inglaterra, la Monarquía pidió al clero a "cada uno en particular con lo que le permitan sus proporciones para el remedio de las graves y urgentes necesidades de la Metropoli y las que al mismo tiempo se padecen en nuestras posesiones de América". El cabildo de México y el arzobispo aportaron 50.000 pesos de la renta decimal en calidad de donación y 100.000 pesos en préstamo, provenientes de los expolios del difunto arzobispo Haro y Peralta (1772-1800) y que se encontraban depositados en las cajas reales mientras se decidía su destino. Otros 50.000 pesos entregó la iglesia de Guadalajara, 30.000 de donativo (mitad el cabildo y mitad el obispo) y 20.000 en calidad de préstamo pertenecientes al ramo de fábrica de la catedral. Los capitulares de Valladolid contribuyeron con 75.000 pesos (25.000 pesos en donativo y 50.000 en préstamo). ${ }^{21}$

Entre 1808 y 1810 los gastos para sostener la guerra de España contra la invasión napoleónica motivaron nuevas exigencias de recursos extraordinarios a las colonias americanas. En esos pocos años, el arzobispo y el cabildo de la catedral de la ciudad de México dieron 174.000 pesos para los ejércitos españoles que luchaban en la Península. Otro tanto hicieron el prelado y el cabildo eclesiástico de

${ }^{19}$ Capitales pertenecientes a obras pías y capellanías y disponibles para censos y préstamos que el cabildo invertía en la actividad financiera.

20 ACCMM, AC, libro 59, 23 octubre 1798; AHAG, Haceduría, caja 4; ACADVM, legajo 123. Marichal señala que a partir de 1795 se produjo un aumento de las contribuciones de la Iglesia. Para el autor, esta mayor participación de las instituciones eclesiásticas habría obedecido a la ventaja que encontraron en la garantía ofrecida por la Corona para los préstamos: la pingüe renta del tabaco. Sin embargo, en el caso de las catedrales los donativos fueron más numerosos y en conjunto más cuantiosos que los préstamos. Marichal, La Bancarrota (nota 3), p. 159. Esta lógica crediticia posiblemente se ajuste a las aportaciones de las religiones o clero regular, con una mayor disponibilidad de capitales provenientes de censos, capellanías y obras pías y una destacada participación en el otorgamiento de préstamos.

${ }^{21}$ ACCMM, AC, libro 62, 3 de abril, 4 de abril, 12 de abril y 14 de mayo de 1805; AHAG, Hacienda, caja 4; ACADVM, legajo 123. 
Guadalajara: en septiembre de 1809 donaron 40.000 pesos de la masa decimal, 20.000 pesos del fondo de fábrica y, además, la lámpara mayor y la pila de plata de la sacristía; en mayo y septiembre de 1810 realizaron dos nuevos donativos de 30.000 y 3.200 pesos. Mientras, el capítulo de la iglesia de Valladolid donó 40.000 pesos y prestó a la Hacienda Real otros 40.000 pesos. $^{22}$

La disposición de las catedrales novohispanas a colaborar con las urgencias de la Monarquía se advierte en el valor y la constancia de las aportaciones financieras realizadas. Sin embargo, hacia 1805 los cabildos eclesiásticos comienzan a resentir la presión financiera que venían soportando desde el último decenio del siglo XVIII. Continuaron otorgando recursos para los compromisos bélicos de la Corona, pero también expusieron al virrey el pormenor de las cargas a que estaban sujetos los individuos y ramos de la catedral por los donativos hechos en las guerras anteriores. Manifestaron que era un error pensar que la renta decimal por cuantiosa fuese inagotable. ${ }^{23}$

A partir de la información disponible, entre 1793 y 1810 los capítulos catedrales de México, Valladolid y Guadalajara otorgaron 23 donativos y siete empréstitos. El monto de los donativos rebasó los 712.200 pesos (372.000 pesos del cabildo de México, 175.200 del de Guadalajara y 165.000 pesos del de Valladolid), y el de préstamos alcanzó los 660.000 pesos (150.000 de México, 420.000 de Guadalajara y 90.000 de Valladolid).

¿De qué manera estas aportaciones financieras de las catedrales incidieron en la renta decimal? ¿Por qué los cabildos catedrales sostenían que los préstamos y donativos otorgados a la Corona determinaban el deterioro de sus ingresos por diezmos? Los cabildos eclesiásticos no sólo eran responsables de la recaudación y administración de los diezmos, sino también uno de sus principales partícipes. Cada

22 ACCMM, AC, libro 63, 1 de octubre de 1808; libro 64, 24 de julio y 28 de julio de 1809; 28 de marzo de 1810; 17 de agosto de 1810; 22 de septiembre de 1810; AHAG, libro 16, 12 de septiembre de 1809, 7 de mayo de 1810; ACADVM, legajo 123.

${ }_{23}$ ACCMM, AC, libro 62, 3 de abril de 1805; AHAG, AC, libro 16, 12 de agosto de 1809. En esta década la Monarquía impuso la Consolidación de Vales Reales en la Nueva España. Se trataba de la transferencia de los capitales de capellanías y obras pías a la Real Hacienda. Con esta medida las catedrales veían desaparecer uno de sus ramos, los "depósitos", a partir de los cuales desarrollaban la actividad crediticia y solventaban una parte de los ingresos de sus ministros. Véase: ACCMM, AC, libro 62, 28 de julio de 1809 . 
cabildo recibía el 25 por ciento de la gruesa decimal o diezmo líquido (total recaudado menos los gastos), facción denominada "mesa capitular", a lo que se agregaba en algunos obispados la porción correspondiente a los "cuatro novenos beneficiales" (22\% del diezmo líquido). El monto resultante era prorrateado entre los miembros del cabildo como renta o salario, en proporción al puesto que ocuparan en él. ${ }^{24}$ Cuando las catedrales novohispanas aportaron - de manera voluntaria o forzosa - a las urgencias de la Hacienda Real, lo hicieron, principalmente, mediante tres mecanismos:

Primero, gravaron la gruesa decimal, excepto los dos novenos, con un porcentaje anual destinado al real erario. Segundo, depositaron directamente en cajas reales los montos comprometidos a partir de sumas disponibles en diversos ramos de la administración catedralicia (recaudación decimal, depósitos de capellanías y obras pías, fábrica); luego se procedía a descontar anualmente de la mesa capitular una cantidad fija hasta cubrir el monto donado o prestado del ramo diezmos o hasta reembolsar la suma que se había tomado de ramos ajenos. Por ejemplo, cuando en 1798 el rey solicitó un donativo voluntario de sus súbditos indianos, el cabildo de México acordó:

"[dar] setenta mil pesos, los que se sacarán del ramo de depósitos o del dinero existente siendo dicha cantidad de todos los participes (exceptos los dos reales novenos) y haciéndose prorrata como en los antecedentes donativos y revaxandose anualmente a tres mil pesos [...] y que la rebaja [...] comiense desde este año." ${ }^{25}$

Tercero, otra alternativa, de uso poco frecuente, era la de tomar a réditos un determinado monto de dinero para cubrir la demanda financiera de la Corona, probablemente de capitales de capellanías u obras pías; luego, el pago de este crédito y sus intereses se cargaba a la mesa capitular. $^{26}$

${ }^{24}$ La masa decimal se distribuía en dos partes: la primera se asignaba al obispo y al cabildo eclesiástico en partes iguales; el restante 50\% se dividía a su vez en nueve partes que se distribuían entre la Real Hacienda (dos novenos de su majestad), los párrocos y otros ministros del culto ("cuatro novenos"), los hospitales ("1 y $1 \frac{1}{2}$ noveno de hospital") y la fábrica de la iglesia catedral ("1 y 1 1/2 noveno de fábrica"). Óscar Mazín, Archivo capitular de administración diocesana. Valladolid-Morelia. Catalogo I (Zamora 1991), pp. 22-25.

${ }^{25}$ ACCMM, AC, libro 59, 24 de octubre de 1798 (cursiva mía). En la mayoría de los acuerdos de cabildo sobre empréstitos/donativos se establecían los montos y plazos de las deducciones a que quedaba sujeta la mesa capitular.

26 ACCMM, AC, libro 58, 9 de enero de 1793. 
Es decir, con las frecuentes exigencias de donativos y empréstitos por parte de la Corona, la mesa capitular o, lo que es lo mismo, los ingresos decimales que pertenecían al personal de las catedrales quedaron afectados a constantes deducciones anuales, llamados "créditos pasivos" o "deuda nacional", deudas que cada año se iban reintegrando de las rentas de los capitulares. En último término, cada miembro del cabildo eclesiástico solventaba con sus estipendios (fracción del diezmo) el préstamo o donativo realizado a la Corona a título de cuerpo colegiado - arreglo financiero que el cabildo de México explicaba al virrey:

“[...] vuestra excelencia conoce igualmente que los [donativos] que hace este cavildo (a diferencia de los de otros cuerpos) que salen o ya de sus fondos comunes o de los intereses que están a su cargo son por la maior parte deducidos de la renta de sus individuos." 27

Descuentos similares se daban cuando los aportes financieros de los arzobispos y obispos se realizaban mediante los ingresos de diezmo que correspondían al prelado (mesa episcopal). ${ }^{28}$ De esta manera, los partícipes eclesiásticos del diezmo quedaron sujetos a un prolongado endeudamiento que aumentó al ritmo de las crecientes urgencias de la Monarquía. En 1805 el cabildo de la catedral de México expresó que para aquel año sus rentas decimales se encontraban gravadas "en más de cincuenta mil pesos", resultado de los donativos que el cuerpo llevaba hechos al rey desde $1790 .{ }^{29}$

Las frecuentes contribuciones y su repercusión en los fondos de la mesa capitular serían invocadas por los cabildos al momento de responder a nuevas demandas de la Corona:

“[...] todavía los individuos de este cabildo están pagando con sus rentas los quantiosos donativos que ha hechos a su majestad para sus urgentes y graves necesidades y pasara mucho tiempo sin poder completar la paga a esto se agregan otras obligaciones con que están grabadas sus prebendas.” 30

27 ACCMM, AC, libro 58, 27 de abril de 1795.

${ }^{28}$ Por ejemplo: ACCMM, AC, libro 62, 14 de mayo de 1805.

29 En 1809 el cabildo ofrecía algunas cifras generales de estas deudas: "hallarse esta santa iglesia tan sumamente gravada que el total de sus fondos no alcanzan ni aun para sus actuales créditos pasivos originados [en] donaciones hechas al rey de 335.653 pesos que desde el año de 92 hasta el presente, de que aun se deven 160.335 pesos que anualmente se van reintegrando de las rentas de los capitulares". ACCMM, AC, libro 64, 28 de julio de 1809.

${ }^{30}$ ACCMM, AC, libro 63, 1 de octubre de 1808. Véase también: AHAG, Haceduría, caja 4. 
De este modo, en los últimos decenios coloniales la demanda de recursos extraordinarios para solventar las sucesivas guerras contra las potencias europeas alteró profundamente el balance establecido entre los destinatarios últimos de la fiscalidad eclesiástica. La distribución de la renta decimal se modificó en términos reales - no nominales - en beneficio de uno de los partícipes, la Corona, en detrimento de los partícipes eclesiásticos. De manera creciente, la Real Hacienda recibió recursos provenientes del sistema fiscal eclesiástico, de los estipendios de los miembros de los cabildos eclesiásticos en sus respectivas diócesis en tanto destinatarios del diezmo. Se verificaba así un cambio en la distribución o reparto de los ingresos resultantes del impuesto eclesiástico; este cambio complementó las transferencias fiscales al erario que ya se venían realizando de los fondos del diezmo mediante el cobro de vacantes (transferencias a las cajas reales de la porción de diezmos correspondientes a los beneficios vacos hasta el nuevo nombramiento) e impuestos que cargaban los ingresos de los partícipes eclesiásticos de la masa decimal (media anata, anualidad y subsidio). Las transferencias decimales a la Real Hacienda se ampliaron en 1804 con la exigencia del "nuevo noveno", equivalente al $11 \%$ por ciento de la renta decimal (novena parte del total recaudado). Todos medios por los cuales el diezmo contribuyó a la fiscalidad y al crédito público, dentro de un proceso, definido por Marichal como de progresiva subordinación económica del poder eclesiástico al civil en los últimos decenios del siglo XVIII. ${ }^{31}$

\section{LA FISCALIDAD ECLESIÁSTICA Y LA GUERRA DE INDEPENDENCIA}

Al momento de inicio de la guerra de Independencia, el erario novohispano se encontraba exhausto por la continua extracción de recursos hacia la metrópoli. Los arbitrios necesarios para el enfrentamiento armado con las tropas insurgentes fueron solventados por las corporaciones locales; con ello, nuevos donativos y préstamos gravaron los ingresos del diezmo novohispano. Durante la década de 1810, las catedrales cedieron diversas cantidades a las instancias del

\footnotetext{
${ }^{31}$ Marichal, La Bancarrota (nota 3), p. 145.
} 
poder real en la Nueva España (virrey, Audiencia, juntas de alistamiento de batallones y a los cuerpos patrióticos encargados de la defensa de las ciudades), al tiempo que continuaron aportando a los gastos de los conflictos armados en la Península Ibérica, al menos hasta $1812 .{ }^{32}$

Sin embargo, el mayor cambio registrado en la fiscalidad eclesiástica durante la guerra de Independencia se produjo en la recaudación del diezmo. Los gráficos 1 y 2 muestran el pronunciado descenso de los montos de la gruesa decimal repartible (diezmo líquido) a partir de 1810 en el Arzobispado de México y en el Obispado de Michoacán. En el obispado de Guadalajara la falta de información para esos años impide construir la curva de diezmos; sin embargo, algunas cifras disponibles señalan la misma disminución en los montos recaudados: la gruesa decimal de 1800 alcanzó la cifra de 440.000 pesos, mientras que la de 1810 sólo 189.628 pesos. $^{33}$

GRÁFICO 1:

Diezmos del ArzobisPado de MéXICO, 1790-1825.

Montos ANUALES EN PESOS

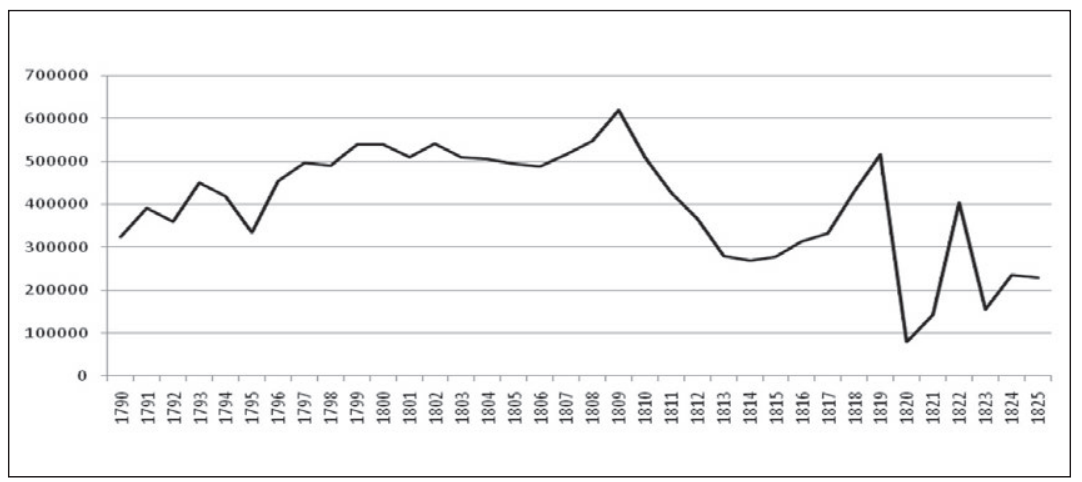

Fuentes: ACCMM, Contaduría caja 3, 4 y 9; rollo 16.

32 Bravo/Pérez, Una iglesia (nota 5), pp. 326-330; AHAG, Gobierno, caja 8, AC, libros 15-16; ACADVM, legajo 123, AC, libro 44, 6 diciembre 1811.

33 AHAG, Diezmos, caja 7. 
GRÁFICO 2:

Diezmos del Obispado de Michoacán, 1790-1825.

MONTES ANUALES EN PESOS.

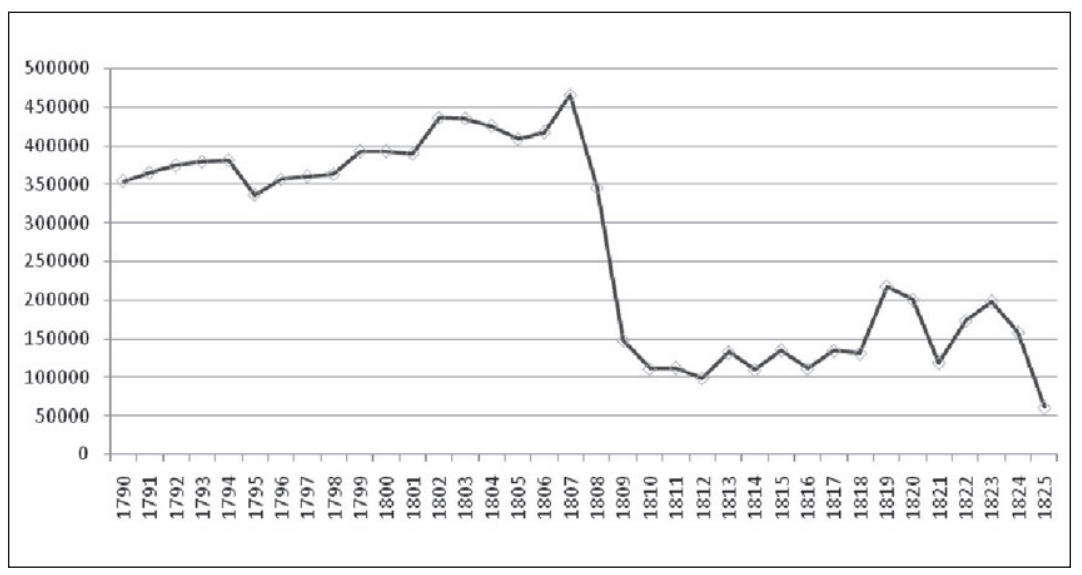

Fuentes: ACADVM, Cuadrantes caja 1; legajos 123 y 172.

La guerra afectó el sistema de cobro del diezmo establecido por las catedrales. La eficacia de la recolección de la fiscalidad eclesiástica se apoyaba principalmente en la articulación entre los jueces hacedores y los diezmeros (colectores o administradores). Los primeros eran miembros del cabildo eclesiástico, responsables de organizar y controlar la recolección decimal: se encargaban del nombramiento de los recaudadores en cada distrito decimal; establecían las formas de cobro del diezmo y del registro de las partidas; vigilaban estrechamente la labor de comercialización de los productos; y verificaban las cuentas presentadas. Los segundos eran los encargados de cobrar el diezmo dentro de una jurisdicción decimal o colecturía, de almacenar el grano y los animales en las casas y corrales de la colecturía, así como de realizar su venta y de llevar el dinero obtenido a las catedrales. Los conflictos armados de la Independencia provocaron el deterioro de las unidades de recolección fiscal que eran las colecturías y en muchos casos la ruptura de la comunicación de los colectores con los jueces hacedores del cabildo.

Al poco tiempo del levantamiento de Hidalgo, comenzaron a llegar a los jueces hacedores de México los informes de los diezmeros sobre las pérdidas de semillas, ganados y metálico como consecuencia 
de la ocupación y saqueo de las casas colecturías por los insurgentes. ${ }^{34}$ Para enero, 14 de las 25 colecturías de la arquidiócesis se encontraban ocupadas $;{ }^{35}$ el metálico disponible en las colecturías y los productos depositados en sus trojes y corrales se convirtieron en bastimentos de las tropas insurgentes. En el Obispado de Guadalajara, además de los diezmatorios, la misma catedral sufrió el saqueo de los caudales decimales guardados en la clavería cuando partidas de insurgentes entraron en la ciudad. ${ }^{36}$ Asaltos y ocupaciones análogos señaló, en 1817, el cabildo de la iglesia vallisoletana:

"[...] desde el principio robó el infame Hidalgo los caudales que existían en las arcas de esta clavería pertenecientes al año 1808 y repartibles en fines del de diez, lo mismo hicieron los viles sectarios de aquel apóstata por casi todos los diezmatorios de la diócesis, saqueando y destruyendo quanto había en ellos, así en dinero como en semillas [...]. De cincuenta diezmatorios que tiene la mitra, treinta y siete desde el principio de la rebelión ha estado siempre y estan todavía en poder de los rebeldes y nada se ha percibido de ellos." ${ }^{37}$

En algunas zonas los insurgentes prohibieron a los colectores de las catedrales cobrar el diezmo; por ejemplo, el administrador de diezmos de Valladolid explicó la dificultad que tenía para contratar ayudantes para la colectación porque los insurgentes "les tienen notificada pena de la vida si recaudan un grano". ${ }^{38}$ En su lugar, las tropas insurgentes pusieron sus propios recaudadores. ${ }^{39}$

Los insurgentes no fueron los únicos en aprovechar las colecturías o diezmatorios como puntos de abastecimiento. Los comandantes militares del Ejército realista también dispusieron de los granos, animales y pesos de la recaudación del diezmo. En 1817 el cabildo de Valladolid expresó que "en los diezmatorios en que se ha recogido y recoje algo, casi todo ha sido y es para las tropas de su magestad" y que "los comandantes exigen el diezmo como cosa propia". ${ }^{40}$ Los capitulares de las catedrales se esforzaron por ejercer algún

${ }^{34}$ ACCMM, AC, libro 65, 21 noviembre 1810; libro 66, 1 de junio de 1813.

35 Bravo/Pérez, Una iglesia (nota 5), p. 278.

${ }_{36}$ AHAG, Haceduría, caja 2; AC, libro 16, marzo de 1815; Gobierno, cajas 7 y 8.

37 ACADVM, legajo 157.

38 ACADVM, legajo 114.

39 ACCMM, Haceduría, caja 26, expediente 1. Otro ejemplo: ACCMM, AC, libro 67, 12 julio $1814,183 \mathrm{v}$.

40 ACADVM, legajo 157. En el obispado de Guadalajara, los diezmos de Zacatecas (87.977 pesos) fueron decomisados por orden del virrey para cubrir los gastos de las tropas. AHAG, Gobierno, caja 7. 
control sobre estas entregas, ordenando a los colectores que solicitaran "boletas" o comprobantes de los bienes suministrados a las tropas del rey. ${ }^{41}$

Para proteger los frutos decimales almacenados del "saqueo y robo" de las tropas insurgentes y de la ocupación "por personas impedidas por derecho de administrarlos", los cabildos eclesiásticos optaron por contribuir con cantidades fijas anuales o mensuales que entregarían las colecturías a las juntas patrióticas de los pueblos y a los comandantes militares. A cambio esperaban regular el flujo de recursos decimales hacia las tropas realistas y asegurar la presencia de destacamentos en las jurisdicciones decimales para "alejar a los rebeldes", permitir la colectación y resguardar las trojes. Varios recaudadores informaron que en sus jurisdicciones la recaudación sólo era posible mientras permanecía en el lugar la tropa del rey. ${ }^{42}$ Los colectores recibieron órdenes de contribuir para la formación y el mantenimiento de los batallones patriotas de sus distritos con los llamados "suplementos" o "pensiones". En la diócesis de México, por ejemplo, se graduó en 500 pesos la ayuda de la colecturía de Toluca para el cuartel que necesitaba el Ejército; en Michoacán el diezmatorio de Valladolid tenía asignada una pensión de 400 pesos para el mantenimiento de la tropa, más cuatro caballos y monturas ${ }^{43}$ Pero pese al esfuerzo del cabildo por liberar a las colecturías de las arbitrariedades de los jefes realistas, buena parte de los recursos del diezmo que lograban colectarse siguieron fluyendo para solventar los gastos de la guerra a través de préstamos forzosos o confiscaciones. Todavía en 1819, la catedral de Guadalajara solicitaba al Gobierno "se fixe una regla en esta clase de contribuciones extraordinarias para que se contribuya por la iglesia a la causa común sin que se perjudique en desproporción de estos impuestos". ${ }^{44}$

El cobro de gravámenes a las semillas del diezmo fue otra manera de transferir recursos decimales al sostenimiento de tropas realistas en

41 ACADVM, legajo 114.

42 ACCMM, AC, libro 66, 29 de agosto de 1812; libro 67, 23 de noviembre de 1813; AHAG, Haceduría, caja 2.

${ }^{43}$ ACCMM, AC, libro 65, 2 de abril de 1811; ACADVM, legajo 114. El cabildo eclesiástico de Guadalajara sostuvo que se trataba de cargas muy gravosas para las rentas decimales: "las pensiones extraordinarias de guerra se llevan la decima y a ocasiones la octaba parte de los efectos" en cada diezmatorio. AHAG, Gobierno, caja 8.

44 AHAG, Gobierno, caja 7. 
las diferentes localidades. Algunos ayuntamientos gravaron las cargas de granos que se introducían a la casa colecturía del pueblo, y los administradores de alcabalas buscaron cobrar por las compras/ventas de semillas que realizaban los colectores. Estas disposiciones atacaron los privilegios y exenciones fiscales que el diezmo había logrado mantener durante la colonia. ${ }^{45} \mathrm{El}$ colector de Chalco informó al cabildo de la catedral metropolitana que los diezmos de dicha provincia tenían asignada una contribución de " 4 reales en cada carga de maíz, lo mismo en la de cebada y un peso en la de trigo y legumbres"; en San Juan del Río cada carga de maíz y frijol pagaba dos reales, destinados a "la subsistencia de las compañías urbanas en continuo servicio en ese pueblo y jurisdicción". ${ }^{46}$

Entre 1817 y 1818 , se multiplicaron los intentos de las aduanas foráneas de cobrar alcabalas a los diezmos. Para detener este avance fiscal sobre las rentas decimales, el cabildo catedral de México dispuso que se tratase con el director de la Real Aduana sobre el particular. Luego se envió una representación al virrey y otra al Consejo de Indias. Al parecer, la resistencia del cabildo tuvo éxito y el pago de la alcabala del diezmo no logró instalarse. En algunos casos la insistencia de los administradores de alcabalas se redujo tras la entrega de un donativo para las tropas de la localidad. ${ }^{47}$

La guerra provocó, además, la deficiente administración de las colecturías. A la imposibilidad de recolectar el diezmo en las zonas ocupadas por los insurgentes se sumó el abandono de los distritos decimales por los colectores durante largos periodos, la renuncia de algunos debido a las insuficientes cantidades que conseguían recaudar y la incorporación de otros al Ejército realista. En 1816 el número de colectores que residían en la ciudad de México era tan considerable que el cabildo acordó "que los jueces hacedores estrechen providencias de que se les obligue a ir a su destino". ${ }^{48}$ En 1817 el cabildo ecle-

45 Durante el Antiguo Régimen la Iglesia pretendió y defendió con éxito la inmunidad fiscal de los eclesiásticos y de sus bienes. Artola, Hacienda (nota 2), p. 57.

${ }_{46}$ ACCMM, AC, libro 66, 1 de agosto de 1812. Ejemplos similares: AHAG, libro 16, 3 de diciembre de 1815; ACADVM, legajo 108.

47 ACCMM, AC, libro 65, 1 de agosto de 1812; libro 67, 23 de septiembre de 1813 y 31 de octubre de 1813; libro 68, 28 de noviembre de 1817; 17 de abril de 1818; libro 69, 14 de julio de 1818. En la documentación revisada para los obispados de Michoacán y Guadalajara no aparecen registros de intentos de cobro de la alcabala al diezmo.

48 ACCMM, AC, libro 68, 30 de abril de 1818. 
siástico de Valladolid reconoció que en algunos diezmatorios no había quien quisiera encargarse de la administración porque "dan poco y por la amenaza de los rebeldes". ${ }^{49}$

Para contrarrestar la emigración de los colectores y la consecuente paralización del cobro del diezmo en algunas jurisdicciones, el cabildo del México resolvió aumentar los sueldos de los colectores y, en caso necesario, nombrar administradores interinos o asignar la responsabilidad de la recolección al colector de la jurisdicción vecina. Conocedores los capitulares de los "miserables y mezquinos rendimientos" de algunas colecturías propusieron la unificación de dos jurisdicciones decimales con el objeto de dotar mejor al colector. En el caso de la colecturía de Chilpancingo, para la cual era imposible encontrar recaudador "por no sufragar la renta asignada ni aun los gastos que impenden", el cobro de los diezmos fue encargado a los curas de aquel territorio. ${ }^{50} \mathrm{El}$ cabildo eclesiástico de Guadalajara, por su parte, intentó que los administradores permanecieran en sus cargos, rechazando las renuncias que varios habían exhibido en 1812 y ordenándoles que continuaran por el tiempo que habían sido nombrados. La medida no resolvió el problema, pues a los pocos meses los jueces hacedores se encontraron intentando nombrar nuevos administradores en numerosos diezmatorios de la diócesis, incluidos aquellos de las renuncias. ${ }^{51}$ En la diócesis de Michoacán hubo administraciones que recién a comienzos de la década de 1820 pudieron ser nuevamente controladas por el cabildo, luego de varios años de "desamparo". 52

La baja recaudación de diezmos también se relacionó con la general decadencia de la producción agropecuaria a causa de la guerra. Los informes de los jueces hacedores manifestaban que durante los años de insurrección se habían agotado las semillas y los ganados y sacado "los brazos utiles para cultivarlos y que se produzcan de nuevo". ${ }^{53} \mathrm{El}$ cabildo vallisoletano sostenía que

49 ACADVM, legajo 157.

${ }^{50}$ ACCMM, AC, libro 68, 30 de abril de 1816; 27 de mayo de 1816; 12 de agosto de 1816.

51 AHAG, AC, libro 16, 9 de diciembre de 1812, 2 de marzo de 1813.

52 Archivo Casa Morelos (en adelante ACM), Cabildo, caja 1354, legajos 13 y 29.

53 ACCMM, AC, libro 66, 19 de febrero de 1812. Un panorama similar de deterioro de la cría de ganados y de la labranza señalaba la Haceduría de Guadalajara para buena parte de los diezmatorios. AHAG, Gobierno, Cabildo, caja 8. 
“[...] aunque el reino se pacifique luego deben pasar tres años para que se pongan al corriente las rentas, y nunca serán sombra de lo que fueron por el general destroso de los ranchos y haciendas, y por el exterminio de los animales necesarios para la agricultura". ${ }^{54}$

Aún con la guerra, en algunas jurisdicciones decimales fue posible recolectar el diezmo y acumular existencias en granos, como en las colecturías de Querétaro y San Juan del Río (Arzobispado de México) o Zacoalco (Obispado de Guadalajara). Sin embargo, la dificultad estuvo en la realización de los productos del diezmo a precios rentables y el traslado del metálico obtenido a las arcas catedralicias. Para los colectores, intentar trasladar los granos a otras poblaciones donde se pagaran mejores precios resultaba poco redituable porque era difícil conseguir arrieros que los condujeran y, cuando se hacía, era usual sufrir el robo de las carretas o bien que el elevado costo del transporte consumiera las posibles ganancias. Al respecto, en 1817 el recaudador de Temascaltepec comunicó al cabildo que "los fletes están mas subidos que antes, devo hacer mayores gastos por consiguiente porque por el flete que antes llevaban un real ahora real y medio o dos reales y así proporcionalmente". El cabildo de Guadalajara también manifestó que el acarreo de los granos costaba casi el doble que antes. ${ }^{55}$

La imposibilidad de trasladar las semillas a los mercados importantes (México, por ejemplo) generó su acumulación en algunas colecturías con el consiguiente riesgo de perderse por los saqueos de los insurgentes o la humedad de la temporada de lluvias. Para evitar mayores pérdidas, los cabildos recomendaban a los colectores vender algunas cargas rebajadas. ${ }^{56} \mathrm{La}$ venta local de los granos del diezmo significaba la obtención de escasos rendimientos, pues sólo se podía vender "a precios ínfimos de modo que no reportan". ${ }^{57}$ La baja valoración de las semillas también se debía a las ventas que realizaban los insurgentes de los productos del diezmo obtenidos del "robo y saqueo", "malbaratándolos a precios menores". ${ }^{58}$

54 ACADVM, legajo 157.

55 ACCMM, Haceduría, caja 26; AHAG, Gobierno, Cabildo, caja 8.

56 ACCMM, AC, libro 67, s/f 1815. El recolector de diezmos de Tizapán el Alto (obispado de Guadalajara) había encomendado a un empleado suyo tratara de realizar el maíz colectado: "lla sea fiándolo [a] algún seguro, lla sea vendiéndolo y escondiendo el dinero, o bea si en canoas puede conducir alguno a Chapala". AHAG, Gobierno, caja 8.

57 ACADVM, legajo 114.

${ }_{58}$ Bravo/Pérez, Una iglesia (nota 5), p. 287. 
Otra preocupación de los cabildos eclesiásticos fue de qué manera conducir el dinero que lograban reunir los colectores a las claverías cuando los caminos "estaban infestados de gavillas". Una alternativa fue que los colectores entregaran el metálico disponible en la colecturía a los comandantes militares realistas o a los administradores de rentas reales a cambio de libranzas contra las cajas reales de la capital. ${ }^{59}$ Otra fue conceder prórrogas a los colectores para el envío a la catedral del dinero y las cuentas correspondientes cuando, previa averiguación, conocían que las incursiones insurgentes por sus jurisdicciones les impedían realizar las remisiones. A pesar de estas providencias, destinadas a mantener un cierto flujo de envíos, hubo colectores que durante los años de las rebeliones no hicieron "entero alguno respectivo a la gruesa". ${ }^{60}$

Hacia 1817 y 1818 , con la pacificación de la mayor parte de los territorios, la catedral de México intentó reordenar el sistema de colecturías mediante el nombramiento de nuevos colectores en las administraciones que tenían colectores interinos y la verificación de la situación de los fiadores. Pero, sobre todo, trató de revertir "la desidia y morosidad que se nota[ba] en varios colectores en los rendimientos de su administración"; ${ }^{61}$ el cabildo les pidió que inmediatamente se pusieran al corriente con el envío de cuentas y recaudación. Para algunas colecturías, de las que sólo se tenían noticias vagas desde el comienzo de la guerra, se comisionaron informantes e interventores, quienes verificaron el estado de las casas colecturías, los productos almacenados y los libros de cuentas. Las inspecciones del cabildo mostraron que algunos colectores habían aprovechado la guerra como pretexto para encubrir la mala administración en algunos casos y la malversación en otros. ${ }^{62}$ Del mismo, una vez restablecida la comunicación con las jurisdicciones decimales, el cabildo de la catedral de Valladolid intentó reorganizar la recaudación mediante el nombramiento de administradores provisionales en los diezmatorios que no los tenían y de personas de confianza para el control de las cuentas en las administraciones. ${ }^{63}$

${ }_{59}$ ACCMM, Haceduría, caja 26, exp. 1.

${ }^{60}$ ACCMM, AC, libro 69, 26 de noviembre de 1818. Véase Bravo/Pérez, Una iglesia (nota 5), p. 288.

${ }_{61}$ ACCMM, AC, libro 68, 26 de noviembre de 1818.

${ }^{62}$ Tal fue el caso del colector de Cuernavaca, quien desfalcó 22.381 pesos del diezmo de su jurisdicción. Bravo/Pérez, Una iglesia (nota 5), pp. 291-293.

${ }^{63}$ ACM, Cabildo, caja 1354, legajos 13 y 29. 
Los capitulares de Guadalajara, por su parte, se mostraron más inclinados a documentar las cantidades suministradas por los administradores de diezmos a las divisiones de tropas del rey, para presentarlas a las cajas reales o para hacer el descuento correspondiente en los disminuidos repartimientos anuales de diezmos, que a delinear medidas destinadas a reorganizar el sistema de recaudación. Al parecer, el cabildo guadalajarense tenía expectativas de equilibrar sus cuentas, exigiendo el reconocimiento de los recursos facilitados a los comandantes de tropas y solicitando al virrey la devolución de los préstamos realizados a la Hacienda Real. ${ }^{64}$

Algunos colectores manifestaron que la tardanza en presentar las cuentas de su administración y los fondos recaudados se debía a la morosidad de los causantes de diezmos - situación confirmada por los visitadores de las colecturías. Para 1818 los años de la guerra violenta habían terminado y los combates se hallaban circunscriptos a unas pocas regiones; ${ }^{65}$ los jueces hacedores esperaban que la colectación se regularizara, que los recaudadores "como a esta fecha ya deben haber cobrado los mas de los rendimientos de su administración, ya debían haber realizado muchas exhibiciones de consideración". Sin embargo, se verificó un considerable atraso en los pagos de los causantes y una importante acumulación de deudas decimales. ${ }^{66}$

Así, los intentos de los cabildos catedrales de reorganizar el sistema recaudatorio fueron rebatidos por las cartas de visitadores y colectores que daban cuenta de la negligencia e incumplimiento en los pagos observados en sus jurisdicciones. En el Arzobispado de México, el recaudador de Malatepec, de regreso a su distrito en 1817, señaló que no había conseguido las manifestaciones de diezmos de los "principales" del lugar; situaciones similares de impago de diezmos se registraban en Tacuba, Chalco y Azcapotzalco. ${ }^{67}$ El administrador de Guadalajara informó a los jueces hacedores de la "situación lamentable" de ese diezmatorio por la falta de contribución de los causantes; en tanto, el administrador de Zinapécuaro señaló al cabildo catedral de Valladolid las dificultades que tenía para conseguir las manifestaciones

${ }^{64}$ AHAG, 12 marzo 1816; AC, libro 16, 24 de octubre de 1818; 8 de enero de 1819; Gobierno, Cabildo, caja 8.

${ }^{65}$ Luis Villorio, "La revolución de independencia": El Colegio de México, Historia general de México: versión 2000 (México, D.F. 2009), pp. 491-523, aquí: p. 516.

66 ACCMM, AC, libro 68, 26 de noviembre de 1818.

${ }_{67}$ ACCMM, Hacienda, caja 26, exp. 1; AC, libro 69, 16 de mayo de 1820. 
de los causantes "porque de mil apenas si le firman una". Explicó, además, la falta de cobro de amachorrados y conmutaciones por una notable resistencia al pago: de los primeros nada se recogió en el año a que se refieren por lo insolentado de los matadores de ganados que en la mayor parte eran insurgentes y por lo segundo comenzó

"[...] el arreglo en los pueblos desde que [...] se estableció la tropa del rey; entré en composición con ellos y por lo que adeudan se les concedieron plazos que aunque cumplidos han satisfecho en muy poco." ${ }^{68}$

Los problemas de fraude y de resistencia al pago fueron un rasgo estructural de la fiscalidad eclesiástica desde su establecimiento. Aunque era un fenómeno antiguo cuyo rastro puede seguirse en los intentos de los indios o de los jesuitas por no ser considerados sujetos pasivos de diezmar y en los sermones y cartas pastorales que condenan las maniobras de los productores de ocultar una parte de la base imponible o de entregar los frutos de peor calidad, con la guerra de Independencia se aprecia un punto de inflexión, un descenso general de la renta decimal sin retorno, comprensible - a mi juicio - por la resistencia de los causantes. La guerra afectó negativamente los rendimientos decimales de las diócesis, pero además habría promovido el establecimiento de una defraudación de proporciones, perceptible en las curvas de recaudación anual de diezmos, las cuales aún con el restablecimiento de la paz (1821) no lograron recuperarse a los niveles previos a la guerra (gráficos 1 y 2). En el Obispado de Guadalajara la recaudación decimal de 1823 fue de 101.860 pesos, lejos de la cifra de 387.304 pesos de 1808 , por ejemplo. ${ }^{69}$

Los fieles conocían perfectamente la obligación de diezmar. Sin embargo, "una vez contenido el desorden", algunos continuaron eludiendo el pago. La guerra debió aumentar la capacidad de los causantes para defraudar el diezmo. Las posibilidades de un contribuyente de realizar con éxito fraude fiscal dependían de un "conjunto de factores, que jugaban a favor o en contra de la capacidad del perceptor para detectarlo y, en su caso, perseguirlo". ${ }^{70}$ En el caso de la fiscalidad eclesiástica, durante la guerra de Independencia se produjo la reducción

${ }^{68}$ ACADVM, legajo 114 y 108.

${ }^{69}$ AHAG, Diezmo, caja 7.

70 Para el diezmo, Ángel Fernández González señala los siguientes: dedicar la tierra a cultivos exentos; el número de pagadores y la dispersión geográfica; el policultivo que dificultaba el control; el apoyo de las autoridades civiles que dificultaba el fraude. Ángel Fernández González, "Las estrategias antifiscales en las sociedades campesinas tradicionales. Galicia, 1700-1840”: El fraude fiscal (nota 4), pp. 123-143, aquí: p. 127. 
de la capacidad operativa de los aparatos de vigilancia y control de los cabildos eclesiásticos (perceptores del diezmo), a causa de la desarticulación del sistema de recaudación de colecturías (ocupación de los insurgentes, robo y saqueos de los productos del diezmo, emigración de los colectores, desfalcos, dificultades de comercialización, etc.). Particularmente, el ausentismo, la deserción y los continuos reemplazos de los colectores habrían dificultado el conocimiento de los volúmenes habituales de cosecha, el seguimiento del proceso productivo y el ajustado pago de los causantes. Además, el conflicto bélico y la inestabilidad política que le siguió, probablemente, redujeron el auxilio del poder civil al ejercicio de la fiscalidad eclesiástica, aminorándose con ello la capacidad de la Iglesia para perseguir el impago de los causantes del diezmo.

Considerar, aunque brevemente, los factores ideológicos y el sistema de valores de los productores respecto a las exigencias fiscales abona elementos para sostener la idea de una persistente defraudación decimal en esta etapa. Si el contribuyente sentía que el impuesto era gravoso trataría de escapar al pago del impuesto. Con la guerra y sus consecuencias económicas los pequeños productores vieron disminuidos sus ingresos reales, reducidas sus posibilidades de vender su fuerza de trabajo y limitadas sus posibilidades de emigrar o de acudir a la ayuda de parientes. Para los hacendados, conseguir trabajadores se volvió dificultoso, así como trasladar la cosecha a los mercados con mejores precios. Resulta claro que en estas circunstancias derivadas de la guerra el diezmo habría sido como una carga excesiva o injusta que obligaba al contribuyente a renunciar a muchas cosas necesarias; percepción que induciría, según Einaudi, al fraude y a ciertas transacciones con la conciencia, e incluso a esperar la indulgencia de la sociedad y del perceptor. ${ }^{71}$ Otro valor presente en las estrategias antifiscales campesinas era suponer que en momentos de crisis de subsistencia los preceptores ajustarían sus exigencias a la mermada capacidad de pago de los productores. No se niega abiertamente el pago del diezmo, sino que se espera que la Iglesia sea flexible ante el retraso, por encontrarse los causantes imposibilitados de cumplir por los efectos negativos de la guerra. ${ }^{72}$ Esta clase de argumento aparece en una carta del colector de Toluca:

${ }^{71}$ Einaudi sostiene que, desde el punto de vista económico, el contribuyente estará más dispuesto a "exponerse a una sanción y a las molestias que puede experimentar si el fraude se descubre" si la alicuota es tan "fuerte" que existe la conveniencia de la evasión. Luigi Einaudi, Principios de la Hacienda pública (Madrid 1962), pp. 210-212.

72 Fernández González, "Estrategias antifiscales" (nota 70), p. 129. 
“[...] creyendo que vale más en las presentes circunstancias dexar en poder de los causantes los pocos o muchos diezmos que hayan causado, hasta mas oportuna ocación que exigírselo en este tiempo en que los enemigos están encima."73

Probablemente, los capitulares de la catedral de Valladolid tenían presente esta mentalidad fiscal de los fieles cuando advirtieron al nuevo administrador de Purungueo que en el cobro de los atrasos tuviese en consideración "los quebrantos que hallan sufrido los causantes con motibo de los destrosos de la insurreccion". ${ }^{74}$

La consideración del carácter útil o no del destino dado a la recaudación es otra actitud social frente a las contribuciones fiscales a tener en cuenta. ¿Era aceptable el uso que se le daba al impuesto $?^{75}$ Durante la guerra de Independencia el cobro del diezmo no se interrumpió, pero los insurgentes y los realistas lo utilizaron como un impuesto de guerra. Las pensiones para armar tropas patrióticas, las confiscaciones, los robos de semillas y ganado de las colecturías y los "colectores insurgentes" alejaban al impuesto eclesiástico de su naturaleza de precepto religioso, destinado al sostenimiento de los ministros y del culto divino. La utilización de las rentas decimales durante la guerra de Independencia para financiar el conflicto habría favorecido la aparición de ciertas concesiones de conciencia en los fieles respecto a su obediencia de la obligación de diezmar.

El deterioro en la puntualidad de los causantes de diezmos a partir de la guerra aparece en un informe de la Haceduría de la catedral de Guadalajara de 1814: en él se señala que, entre otros factores, las rentas decimales se habían reducido "porque muchos eluden el pago de lo que debían, bien con el pretexto de sus atrasos, o bien a la sombra de las dificultades que para estrecharlos ofrecen las actuales circunstancias". ${ }^{76}$ La fidelidad al pago del diezmo había sido minada por la guerra y ya no se repondría en los años que siguieron al fin del conflicto.

73 ACCMM, AC, libro 67, 12 de julio de 1814. Otro ejemplo en AHAG, AC, 20 de junio de 1815.

74 ACM, Cabildo, caja 1354, legajo 13.

75 Francisco Comín, Historia de la Hacienda pública, tomo 1: Europa (Barcelona 1996), pp. 224-226.

${ }^{76}$ AHAG, Gobierno, caja 8. Un ejemplo similar en: ACCMM, AC, libro 68, 19 de junio de 1819 . 


\section{Consideraciones FinAles}

El estudio realizado permite señalar algunos cambios en la fiscalidad eclesiástica en esta etapa marcada por las necesidades financieras y los conflictos de la guerra. En primer lugar, las demandas de la Corona en forma de préstamos y donativos fueron satisfechas por los miembros del alto clero (arzobispos, obispos, cabildos eclesiásticos), la mayoría de las veces, afectando la "gruesa decimal". Así, el aporte de las catedrales a las guerras imperiales aumentó la participación de la Corona en los rendimientos del diezmo a expensas de los partícipes eclesiásticos.

En segundo lugar, el aceitado sistema de recolección decimal, asentado en el estricto control de los colectores - y a través de ellos de los causantes del diezmo -, resintió las exigencias de recursos y el desorden provocados por la guerra de Independencia. Se consumieron semillas, ganados y dineros del diezmo y se produjo la desarticulación de los mecanismos que garantizaban su recaudación.

Finalmente, la etapa insurgente habría generado consecuencias durables para la fiscalidad eclesiástica: el desbarajuste de los mecanismos que garantizaban el cobro del diezmo suscitó en algunas zonas la interrupción durante largos periodos de la fidelidad decimal de los causantes, con las predecibles dificultades que implicaría intentar restablecer el cumplimiento regular de la obligación fiscal/precepto religioso. Todavía es necesario un análisis más detenido sobre el fraude en la fiscalidad eclesiástica en México, pero la revisión preliminar de la documentación revela la existencia de un aumento en el impago de diezmos frente al debilitamiento de la administración decimal durante la guerra.

Los estudios sobre diezmos en México tienden a centrarse en el fin de la coacción civil para el pago del diezmo (1833) como momento de cambio en el diezmo colonial; sobre todo privilegian las ideas y medidas liberales antidecimales en la explicación del descenso de la recaudación del impuesto eclesiástico. ${ }^{77}$ Esta investigación pone de manifiesto que en la Arquidiócesis de México y los Obispados de Michoacán y Guadalajara las demandas de la guerra alteraron el reparto, desde 1790, y el cobro, a partir de 1810, de la mayor renta eclesiástica: el diezmo.

77 Véase Michael Costeloe, "La administración, recolección y distribución de los diezmos en el arzobispado de México, 1800-1860": Arnold Bauer (comp.), La Iglesia en la economía de América Latina siglos XVI-XIX (México, D.F. 1986), pp. 101-128. 